\title{
TRAINING OF BIOLOGISTS
}

A

CONFERENCE arranged by the Institute of

Biology to discuss the training of biologists in all spheres of their activity was held during April 1718 at The Polytechnic, Regent Street, London.

The problems discussed during the first session were largely those concerned with the early training of biologists in the schools. The first speaker was Mr. Hugh P. Ramage, chairman of the panel which framed the proposals of the Science Masters' Association and the Association of Women Science Teachers ${ }^{1}$. Their view was that all pupils should pursue a balanced course of scientific study up to the sixth form. In the sixth form, regardless of their special aims, all should continue with a broad 'general study' of science; if they were scientists the detailed factual content of their Advanced Level courses should be reduced. Dr. L. H. Finlayson (University of Birmingham), discussing the Biology Panel report in the Gulbenkian inquiry ${ }^{2}$, endorsed the view commonly shared that the separate disciplines of botany and zoology should be abandoned in favour of the single subject biology; this would allow better opportunity for young biologists to acquire essential collateral training in chemistry, physics and perhaps mathematics. Both he and Mr. D. A. Coult (University of Liverpool) discussed the as yet unconfirmed proposals of the Northern Universities Joint Matriculation Board Biology Panel for a syllabus in which a synthesis of these two reports had beon attempted. It had been accepted that the basic language of biology could well be taught by reference to mammals and flowering plants, but that thereafter the Northern Universities Joint Matriculation Board Panel had adopted (with modification) the Gulbenkian proposals, whereby essential biological principles were taught with complete freedom of choice of illustrative material on the teacher's part. Only by this means could individual enthusiasms be encouraged; it was planned to provide fairly extensive notes to help teachers who needed more guidance. Many speakers expressed anxiety about the text-book situation and the need not only for good 'narrative' accounts of biological fields in which exciting advances have been made, but also for help in teaching biology as an experimental science. Considerable criticism was voiced about the value at this stage of the demand for detailed dissection of the rat. It was pointed out that even if the demand for a detailed dissection could be justified, the rat was almost an economic necessity for all but the small examining bodies.

Prof. C. T. Ingold (Birkbeck College, London) and Prof. B. M. Jones (Aberystwyth) discussed university requirements for entry into botanical and zoological departments respectively. Both agreed that most freshmen would be all the more acceptable for having received some training in mathematics and the physical sciences in addition to biology, but that it would always be a pity if this precluded entry for the naturalist with no aptitude for the physical group of scionces. Both agreed also that a wide spread of at least three, if not four, Advanced Level subjects was desirable, and, should this prove too great a load, the proper remedy was surely to reduce the factual content of syllabuses. Prof. Jones, supported by Dr. S. J. Pirt
(Queen Elizabeth College, London), advocated the reintroduction of subjects at a lower level (effectively the old subsidiary level of the Higher School Cortificate) in order to make the spread more realizable. It was greatly to be hoped that by this means sixth. form pupils with a flair for chemistry and physies could also be introduced to biology.

The second session of the conference was concerned with the teaching of biology in the universities, and was opened by Prof. J. W. S. Pringle (Oxford), who analysed the problems of teaching in twenty-nine departments of zoology. Variations wero to be seen in respect of exemption from first-year work on the basis of good Advanced Level qualifications, and on the amount of specialization allowed in the last (third or fourth) year of the course. Generally speaking, he: said, a measure of specialization was found inevitable. but should never be allowed to prejudice the essentially broad training for a first degree. Nevertheless, comparative anatomy should always leave time for teaching those non-taxonomic aspects of zoology which gave true integration to the course. The problem, as he saw it, was to reconcile the slowermoving evolutionary studies, attractive to the naturalists, with the newer experimental fields in which the pace is at present being set. $\mathrm{He}$ then outlined the projected first-year biology course at Oxford, which includes physics, chemistry and geology for biologists, who in their own right also take a course including : genetics, general physiology. taxonomy, evolution and ecology. This can then lead on in subsequent years to more specialized studies of plants and animals, of which systematic study is only one aspect. It was planned also to provide for instruction in biology to postgraduate physicists and chemists.

Prof. W. O. James (Imperial College of Science and Technology, London) said that his Botany Department was concerned with the training not only of teachers and botanical technologists and the research workers of to-morrow, but also of those who were unlikely to become professional botanists. He spoke strongly in favour of catering more meaningfully for the needs of our teachers; as for potential professional botanists, he pointed out that training must make it possible for such students to understand the language of the cognate sciences, so that communication and co-operation between the sciences might become more fruitful. He was not in favour of a special project in the final year, which as low-grade research often got out of hand, but preferred the student to make a choice of one out of three options, namely, ecology with taxonomy, physiology with plant biochemistry, and mycology with plant pathology. All such options also involved advanced formal teaching and long-term practical work.

Prof. H. E. Street (University College of Swansea) turned to consider the postgraduate training of biologists. He strongly criticized the system of three years' training for a doctorate; first, in that it did not involve enough compulsory formal tuition and. second, because there was such a high pass-rate. He did not believe in the attitude of 'sink or swim' for postgraduates any more than he believed in boosting 
a poor performance, at the last, with all the skills of the supervisor; a middle course was infinitely preferable. He would prefer to see the Ph.D. candidate selected after an M.Sc. year consisting of broadly based formal teaching and an initiation into research, and he deplored the fact that too many candidates with 'lower seconds' were being given postgraduate degrees or diplomas in topics such as microbiology and biochemistry, etc., on the basis of formal tuition alone. Prof. D. J. Carr (Queen's, Belfast) thought that Prof. Street's views might not easily apply to small departments. Dr. K. Mellanby (Nature Conservancy) thought that suitable research stations might play quite an important part in postgraduate training. Prof. A. H. Bunting (University of Reading) asked for a better liaison between schools, universities and research institutions in order to promote better vocational orientation toward the satisfying careers available especially in applied biology. Mr. T. A. Oxley (Civil Service Commission) directed attention to the fact that students could gain valuable experience by taking vacation jobs in Government research establishments, while at a higher level a research fellowship scheme was operated. Details of these could be found in a pamphlet recently published by the Civil Service Commissioners and entitled The Scientific Civil Service.

The third session, held on the morning of April 18, fell into two parts. Mr. H. Tristram (University College, London) spoke first on the teaching of microbiology in the universities. He thought that there was some justification for a first degree in microbiology, provided that micro-organisms were used to illustrate the fundamental properties of living organisms, and that a full coverage of all types of micro-organisms was available, cutting across all the traditional boundaries. He emphasized the value of micro-organisms in biochemical teaching; each organism, too, occupied its own ecological niche and demanded a 'naturalist' approach. Practical work should concern itself with fundamental principles, and with experimental techniques which were a means to an end, and not an end in themselves. Entrance requirements for such courses as exist all show a demand for initial training in chemistry, and for preference also in physics and mathematics. Dr. S. J. Pirt (Queen Elizabeth College, London) in a joint paper with Dr. J. R. Postgate (Microbiological Research Establishment, Porton) discussed the desirable training for research in economic microbiology. Having outlined the scope of economic microbiology, he underlined Mr. Tristram's case for non-medical microbiology as a separate and specialized discipline, rather than as a branch of botany. Posts available up to now had largely been filled by chemists, who picked up their microbiology secondhand. A proper training course was to be preferred and should include advanced instruction in chemistry and the physical principles appropriate to aseptic engineering techniques, and enough mathematics to handle quantitative data and to design experiments that could be statistically controlled. He deprecated ancillary training in the macrobiological aspects of botany and zoology, while welcoming the comparative biochemistry of higher plants and animals. To the microbiological disciplines advocated by the first speaker he would add the techniques of tissue culture, and he thought that optional courses in microbial genetics, cytology and ecology would be indispensable. The evolution of microbiology was fast and exeiting, and it demanded a considerable flexibility of approach for the solution of its problems. Prof. D. G. Catcheside (University of Birmingham) thought that, as time was so limited, each course in whatever department should be built around a theme. In Birmingham, for example, microbiology was developed about the theme of the genetic material and its expression. As to the demand for more physics, chemistry and mathematics in biology, he thought that biologists without such training would be squeezed out of a larger increasing part of biology.

Mr. J. B. Copp (general secretary, Institute of Biology) discussed the means whereby biological laboratory assistants in industry and (yovornment service might proceed by an alternative route to full professional status as biologists. At present there were two levels, Ordinary and Higher, of the National Certificate. Since 1957 the Ministry of Education has joined with the Institute in endorsing these certificates for biology. In Scotland candidates have been able to sit for National Certificate examinations in biology since 1961. In England it is proposed to replace the Ordinary National Certificates at present available in scientific subjects with a generalized Ordinary National Certificate in Science. The Ministry has been asked to introduce a Higher National Certificate in biology for subsequent training of those specializing in biology.

Dr. T. G. Onions (Brunel College of Technology) reviewed the institution and progress of the Diploma in Technology in applied biology. This Diploma was open to entry both from schools ('college-based students') and from biological industry ('industrybased students'). The first group predominated and received some of their training with the active co-operation of industry, though as yet industry was not sending many of its own employees for sandwich courses. The academic course was completed by a project and thesis, often the result of ideas stimulated by work with the host organization.

Dr. Onions commented on the need for liberal studies during this period and especially for continued training in the writing of good English. $\mathrm{He}_{\mathrm{e}}$ pointed out that the Diploma in Technology was intended to have the equivalent of graduate status, whether for purposes of proceeding to higher degrees, for full membership of the Institute of Biology, or generally for grading in the Scientific Civil Service.

In discussion at the end of this period, a variety of opinions was expressed about the proposed Ordinary National Certificate in Science so far as biology, now much reduced in content, was concerned. Mr. D. O. Weitzel (Coventry Technical College) felt that a complete revision of syllabuses was required at both Ordinary and Higher Levels. Mr. E. Norris (Ewell County Technical College) suggested a synthesis in which a good background of chemistry, physics. mathematics and English was deliberately slanted towards biology, even though specialization in biology itself was deferred to a later level. It might, however. be necessary, he said, to combine this early general training with a general qualification in biological technology.

The final session was opened by Mr. T. A. Oxley (deputy commissioner, Civil Service Commission). who dealt with the requirements of the Civil Service for biologists. He explained the classification of scientific officer, experimental officer and scientific assistant, pointing out that these categories were also in use in the Nature Conservancy and the Agricultural Research Council, although these bodies 
were strictly separate from the Scientific Civil Service. He gave an analysis of the distribution of biologists of all grades throughout the various Governmental services. He commented on the greater degree of specialization among biologists, which made it more difficult for them to change their field of employment than for, say, physicists. He urged the importance of training in clear thinking and writing of reports. There was a difficulty, he said, in persuading physicists or mathematicians to enter biological research teams, and one remedy would be for biologists with the appropriate flair to read a second degree in either subject.

Prof. F. L. Milthorpe (University of Nottingham) followed with a paper on the type of training suitable for agricultural research. He sketched out the ramifications of the whole agricultural system and stressed the need in a successful course for presenting the basic principles of each of the interrelated disciplines, while keeping the integrated complex in mind. The need for the use of teachers of so many disciplines helped to avoid the inbred narrowness of botany and zoology. As for postgraduate training, he was certain that such training should be by research, that recruitment was to be preferred from a lower level such as plant physiology into a higher level such as agronomy, and lastly, that projects framing a very restricted part of an extensive programme are rarely satisfactory for training in research.

Dr. F. Kingsley Sanders (director, Medical Research Council Virus Research Unit) gave his views on the necessary qualifications for research in virology and molecular biology. Biologists appeared to occupy a rather lowly position in his scheme for selection, unless they had undergone considerable training in physics beforehand.

The final contribution from Dr. W. A. Bain (Smith, Kline and Fronch) dealt with the use of biologists in research and development in the pharmaceutical industry. He thought that pharmacologists were in particularly short supply. Working conditions in industry, he said, compared very favourably with those in universities, both in respect of emoluments, equipment and promotion prospects. He paid tribute to the work of the biological technicians, and voiced the view that industrial firms were less liable to make the mistake of the universities, who had largely failed to appreciate the importance of technical staff in their scientific departments. $\mathrm{H} \Theta$ congratulated the Institute of Biology, which, in conjunction with the Ministry of Education, had promoted the Higher Endorsed Certificate in biology, which should prove invaluable in this field.

In the discussion at the end of the fourth session, disquiet was expressed that in the specialist demand for chemistry, physics and mathematics, biology would be even more than at the present squeezed out of its rightful place in the school. Dr. J. C. Smyth (Paisley Technical College) thought that the Institute's most important task was to improve the public image of biology, especially in the schools, by presenting it as a more rigorous scientific discipline. Mr. D. O. Weitzel (Coventry Technical College) thought that an Advanced Level course of 'background science for biologists' would meet the needs of the schools better than training in Advanced Level mathematics, physics and chemistry.

Mr. R. Weatherall (Avery Hill Training College) spoke of the need for research into the whole educational process. Were it more possible with the aid of the educational psychologists to detect and train real scientific ability, the way would be open for the already urgent reform of the examination system, which in its turn would bring more freedom at all levels to scientific teaching.

The conference was well attended throughout and it was abundantly clear that there is a widespread and lively interest in improving the ways and means of training all categories of biologists during this present explosive period of expansion in biology.

\section{A. Coult}

- Biology for Grammar Schools (A Section of Part I of the Science and Fducation Report of the S.M.A. and A.W.S.T.). (John Murray, 1961.)

${ }^{2}$ Report of an Enquiry into the Suitability of the G.C.E. Advanced Level Syllabuses in Science as a Preparation for Direct Entry into First Degree Courses in the Faculty of Science. (Section $A$ : R
the Biology Panel.) (University of Birmingham. 1959.)

\section{ASPERGILLUS FLAVUS AND TURKEY $X$ DISEASE}

\section{Isolation in Crystalline Form of a Toxin responsible for Turkey $X$ Disease}

$\mathrm{T}$

THE toxin responsible for the so-called Turkey $X$ disease has been described by Sargeant et al. ${ }^{1}$ as a metabolite of the mould Aspergillus flavus Link ex Fries. Flsewhere ${ }^{2}$ wo have describod the examination by thin-layer chromatography of toxincontaining extracts of groundnut meals and cultures of Aspergillus flavus, and presented evidenco which suggests that such extracts may contain more than one substanco toxic to ducklings. This communication is concerned with the isolation in crystalline form of one of these substances from cultures of Aspergillus flavus, and gives an account of some of its physico-chemical properties.

Mould cultures grown on a medium of wetted, crushed sterile groundnuts wore extracted with chloroform/methanol $(2: 1)$. and the residue remaining after evaporation of the solvent defatted by partition between 90 per cent aqueous methanol and light petroleum. The methanol-soluble material was chromatographed on a column of 'Silicagel' ('Mallinckrodt') in chloroform/1 per cent ethanol, and the zone fluorescent in ultra-violet light further purified by thin-layer chromatography on 'Kieselgel $G$ ' (Merck), column chromatography over 'Kieselgel $G$ '/'Celite', and finally, filtration through a short column of alumina. After erystallization from chloroform/ethanol, the recovered material was obtained as gleaming, almost colourless, anisotropic, monoclinic platelets (Fig. 1) which had no sharp melting-point but decomposed at about $220^{\circ} \mathrm{C}$. Seventy-two chromatoplates yielded $40 \mathrm{mg}$.

The same substance, which pending complete structural characterization we refer to as $F B_{1}$, was more simply isolated from liquid cultures of the mould in glucose/ammonium nitrate medium. Chromatography of a chloroform extract of the culture medium 